\title{
The Incidence of Bilateral Well-Differentiated Thyroid Cancer Found at Completion Thyroidectomy
}

\author{
Janice L. Pasieka, M.D., F.R.C.S.C., Norman W. Thompson, M.D., F.A.C.S., \\ Michael K, McLeod, M.D., F.A.C.S., Richard E. Burney, M.D., F.A.C.S., and Mahender Macha \\ Department of Surgery, Division of Endocrine Surgery, University of Michigan, Ann Arbor, Michigan, U.S.A.
}

\begin{abstract}
The purpose of this study was to evaluate the surgical outcome of completion thyroidectomy in patients with presumed unilateral welldifferentiated thyroid cancer (WDTC). The medical records of all patients having had unilateral thyroid lobectomy for WDTC, who subsequently underwent completion thyroidectomy, were reviewed. From 1980 to 1991, 60 patients with WDTC underwent completion thyroidectomy. Fortyseven patients had presumed unilateral WDTC, with no evidence of residual disease prior to their completion thyroidectomy. Twenty-five $(53 \%)$ of these patients were found to have residual neoplastic disease in the neck. In $20(43 \%)$ of 47 patients, a focus of cancer was found in the remaining thyroid lobe and in 5 additional patients no cancer was found in the contralateral lobe, however, unsuspected nodal disease was found. The remaining 13 of the 60 patients presented with either regional recurrence $(n=12)$ or distant metastases $(n=1)$ at the time of their completion thyroidectomy. All ( $92 \%$ ) but 1 of these 13 patients had cancer in the remaining thyroid lobe. Multifocal disease in the primary lobe was associated with bilateral thyroid cancer $(p<0.01)$. Complications were infrequent; transient hypocalcemia occurred in $5(8 \%)$ patients, permanent hypoparathyroidism occurred in $1(1.7 \%)$ patient, and transient recurrent laryngeal nerve palsy occurred in $3(5 \%)$ patients. Residual WDTC was found in $37(62 \%)$ of 60 patients undergoing completion thyroidectomy. Multifocal disease in the primary resected lobe was associated with a high incidence of contralateral thyroid cancer. Completion thyroidectomy is a safe procedure and may prevent the development of regional recurrence by eliminating an unsuspected focus of cancer.
\end{abstract}

The extent of primary surgical resection for well-differentiated thyroid cancer (WDTC) remains controversial. Some surgeons advocate unilateral lobectomy on the affected side, claiming no difference in survival when compared to bilateral thyroidectomy [1-4]. A decreased morbidity is claimed in patients undergoing an unilateral thyroidectomy when compared to patients undergoing a total or near-total thyroidectomy $[1-4]$. Others have recommended a subtotal thyroidectomy for the management of WDTC, removing all of the affected lobe, isthmus and part of the contralateral lobe [5-7]. The rationale for such an approach has been that there is a decreased rate of local recurrence in these patients, when compared to patients

\footnotetext{
Presented at the International Association of Endocrine Surgeons in Stockholm, Sweden, August, 1991.

Reprint requests: Janice L. Pasieka, M.D., University of Calgary, Department of Surgery, Foothills Hospital, 1403-29 Street N.W., Calgary, Alberta, T2N 2T9, Canada.
}

who have undergone an unilateral procedure. Finally, there are those who advocate total or near-total thyroidectomy for patients with WDTC [8-15]. Total thyroidectomy for WDTC has several advantages [16]. First, complete removal of the thyroid gland facilitates the detection, and ablation of metastatic disease with radioactive iodine [17]. Second, thyroglobulin levels are more useful indicators of recurrent disease when nearly all normal thyroid tissue has been eliminated [17-19]. Third, the removal of all thyroid tissue eliminates the small chance of residual WDTC undergoing anaplastic transformation [17]. Fourth, a recent study suggests that there is an improved survival and decreased recurrence rate in patients who have undergone a total or near-total thyroidectomy for WDTC [15]. Finally, a total thyroidectomy eliminates both the primary tumor and any potential residual contralateral cancer. The incidence of this occurring has been reported to be as high as $88 \%$ [11].

Although surgeons and endocrinologists may disagree on the ideal primary procedure for unilateral WDTC, most however, would agree that all thyroid tissue containing thyroid cancer should be removed. The problem arises when one is presented with the patient who has undergone a lobectomy for a thyroid nodule and in whom the diagnosis of cancer was not made until after the operation. Under these circumstances, re-operation is required to remove all remaining thyroid tissue, including any unsuspected contralateral foci of WDTC. Many surgeons have argued that the increased morbidity of re-operative thyroid surgery is too high to justify such a procedure [20]. At the University of Michigan, we advocate total thyroidectomy for WDTC, and recommend completion thyroidectomy for all patients with clinically significant WDTC (tumors $>1.0 \mathrm{~cm}$ ) who have significant residual thyroid tissue remaining in the neck. Significant residual thyroid tissue is defined as thyroid tissue capable of ${ }^{131}$ I uptake $>5 \%$ over 24 hours. However, for the purposes of this study, we limited our study population to those patients who had undergone a unilateral thyroid resection for WDTC. The purpose of this study was to examine the outcome of completion thyroidectomy in patients with presumed unilateral WDTC. Specifically, we wished to determine 
the incidence of residual disease and the complication rate of re-operation.

\section{Methods}

Medical records of all patients who underwent completion thyroidectomy at the University of Michigan Medical Center (UMMC) following lobectomy for WDTC from 1980 to 1991 were reviewed. During this period, $60(21 \%)$ of the 284 patients with WDTC treated at the UMMC underwent completion thyroidectomy as a second procedure. A previous unilateral lobectomy was performed for a solitary thyroid nodule with no clinical evidence of disease by preoperative or intra-operative palpation on the contralateral side in each of these patients. The population under study was divided into two groups. Group 1 underwent prophylactic completion thyroidectomy in the absence of any clinical evidence of either residual, recurrent, or metastatic disease. Group 2 patients underwent therapeutic completion thyroidectomy after presenting with regionally recurrent or metastatic thyroid cancer following a previous unilateral lobectomy for WDTC. Each patient in Group 2 underwent either debulking or complete removal of regionally recurrent WDTC along with a completion thyroidectomy. The histopathology of the initial thyroid specimens were reviewed by a pathologist at the UMMC and the diagnosis of WDTC was confirmed. Completion thyroidectomy was performed either within 7 days of the primary procedure or after a minimum of 3 months.

All completion thyroidectomies were performed using the following approach. The previous scar is excised and the midline between the strap muscles is opened. The isthmus is identified, and any residual pyramidal lobe is excised and included in the surgical specimen. The strap muscles are retracted laterally to allow adequate mobilization of the residual thyroid lobe. This lobe is removed in the manner previously described for total thyroid lobectomy [21]. Parathyroid glands are identified during the dissection and preserved. If there is any question regarding the viability of a parathyroid gland, it is sliced and implanted into the sternocleidomastoid muscle. All enlarged lymph nodes are also removed. Postoperatively, the patient's serum calcium is monitored daily for 3 days and then again on their return visit to the clinic 2 weeks later. Hypoparathyroidism is defined as sustained symptomatic hypocalcemia. Hypoparathyroidism is considered permanent if the patient requires calcium and vitamin $D$ supplements to maintain a normal serum calcium level for 6 months or longer, transient if the patient can be weaned off all supplements within 6 months. Recurrent laryngeal nerve (RLN) injury as a direct result of the completion thyroidectomy is characterized by hoarseness or loss of voice quality and is documented by either direct or indirect laryngoscopy. RLN palsy is defined as transient if there is documented proof of recovery of the RLN by laryngoscopy within 6 months of surgery.

All patients (except those with Hürthle cell carcinoma or the tall cell variant of papillary carcinoma) remained off thyroid hormone supplements following completion thyroidectomy in order to undergo a diagnostic thyroid scan using $2 \mathrm{mCi}$ of ${ }^{131} \mathrm{I}$ six weeks postoperatively. An ablative dose of ${ }^{131} \mathrm{I}$ was given if either the 24 hour percentage of uptake on the thyroid scan was $>2 \%$ or there was uptake lateral the the thyroid bed, represent-
Table 1. Histopathology of patients undergoing completion thyroidectomy.

\begin{tabular}{llll}
\hline & \multicolumn{2}{l}{ No. of pts. } & \\
\cline { 2 - 4 } Histopathology & Group $1^{a}$ & ${\text { Group } 2^{b}}^{b}$ & Total (\%) \\
\hline Papillary & 32 & 9 & $41(68)$ \\
Follicular & 9 & 3 & $12(20)$ \\
Hürthle & 6 & 1 & $7(12)$ \\
\hline \multicolumn{2}{c}{${ }^{a}$ No evidence of residual disease. } & \\
${ }^{b}$ Evidence of residual disease on exam.
\end{tabular}

ing metastatic disease. Following the scan and any subsequent radioactive iodine ablative therapy, all patients were maintained on thyroid hormone. The dose of thyroid hormone was adjusted so that the thyroid stimulating hormone (TSH) was suppressed to the lower limits of detection using a second generation TSH assay, and the patient remained clinically euthyroid. Patients were followed yearly with a clinical evaluation and measurement of serum thyroglobulin levels.

All values are expressed as the mean \pm standard deviation. The Chi-square test was used to test for the significance of comparisons.

\section{Results}

From 1980 to 1991, 284 patients with WDTC were treated at the UMMC. Sixty patients who underwent an initial thyroid lobectomy for presumed unilateral WDTC subsequently underwent a completion thyroidectomy. The indication for the initial surgery was a solitary thyroid nodule in all 60 patients. There were 40 females and 20 males. The average age was $37 \pm 2.2$ years ranging from 6 to 78 years. Two patients had a history of radiation exposure but neither proved to have thyroid cancer in the contralateral lobe. Forty-one $(68 \%)$ patients had papillary cancer, $12(20 \%)$ patients had follicular cancer, and $7(12 \%)$ patients had Hürthle cell carcinoma (Table 1).

The 60 patients who underwent completion thyroidectomy were divided into two groups. Group 1 consisted of 47 patients without any evidence of regional recurrent or metastatic disease who underwent prophylactic completion thyroidectomy. The mean interval to completion thyroidectomy in Group 1 was 8.0 \pm 3.0 months with a range from 1 day to 108 months. In this group, 20 (43\%) of 47 patients were found to have WDTC in the contralateral thyroid lobe. An additional 5 patients had unsuspected positive cervical nodal disease. The positive nodes were found on the side opposite to the primary tumor in 4 of 5 patients. Therefore, a total of 25 (53\%) of the 47 patients with no evidence of disease clinically were found to have residual WDTC (Table 2). The majority of the contralateral tumors in this group, although not detected clinically, were $>1.5 \mathrm{~cm}$ in size (Table 3). All bilateral cancer foci in Group 1 on histopathology were papillary carcinoma. Of the 6 patients with occult papillary carcinoma $(<1.5 \mathrm{~cm})$ found in the contralateral thyroid lobe, 4 of these patients had either follicular or Hürthle cell neoplasms in the primary lobe.

Two patients from Group 1 developed recurrent disease following their completion thyroidectomy at 6 and 12 months, respectively. Both of these patients had residual disease at the time of early completion thyroidectomy (one with bilateral 
Table 2. Residual disease found at prophylactic completion thyroidectomy (Group 1).

\begin{tabular}{llll}
\hline Histopathology $(\mathrm{n})$ & $\begin{array}{l}\text { Bilateral thyroid } \\
\text { cancer }\end{array}$ & $\begin{array}{l}\text { Nodal disease } \\
\text { only }\end{array}$ & Overall \\
\hline Papillary (32) & 15 & 5 & 20 \\
Follicular (9) & $2^{a}$ & 0 & 2 \\
Hürthle cell (6) & $3^{a}$ & 0 & 3 \\
Total (47) & $20(43 \%)$ & $5(11 \%)$ & $25(53 \%)$ \\
\hline
\end{tabular}

${ }^{a}$ Papillary carcinoma found in the contralateral lobe. $\mathrm{n}$ : Number of patients.

Table 3. Size of lesions found in the contralateral thyroid lobe following prophylactic completion thyroidectomy.

\begin{tabular}{lll}
\hline Patients & $<1.5 \mathrm{~cm}$ & $>1.5 \mathrm{~cm}$ \\
\hline Group 1 & 6 & 14 \\
Group 2 $^{b}$ & 0 & 12 \\
\hline
\end{tabular}

${ }^{a}$ No evidence of disease

${ }^{b}$ Evidence of regional recurrence

Table 4. Residual disease found in the contralateral thyroid lobe at completion thyroidectomy in patients with clinical recurrence (Group 2).

\begin{tabular}{ll}
\hline Histopathology $(\mathrm{n})$ & $\begin{array}{l}\text { Bilateral thyroid } \\
\text { disease }(\%)\end{array}$ \\
\hline Papillary (9) & $8(88)$ \\
Follicular (3) & $3(100)$ \\
Hürthle cell (1) & $1(100)$ \\
Total (13) & $12(92)$ \\
\hline
\end{tabular}

$\mathrm{n}$ : Number of patients.

WDTC and the other with regional nodal disease). Both underwent a third operation for excision of their recurrent lateral nodal disease. All patients in Group 1 were alive without evidence of disease at last follow-up. The mean follow-up in this group was $58 \pm 8$ months. Two patients were lost to follow-up at 28 and 21 months, but were free of disease when last seen.

Group 2 consisted of 13 patients who presented with either regional recurrence $(n=12)$ or distant metastases $(n=1)$ and underwent concurrent therapeutic completion thyroidectomy and excision or debulkment of their recurrent disease. The mean time interval before therapeutic completion thyroidectomy was $40 \pm 10$ months ranging from 3 to 120 months. Twelve $(92 \%)$ patients who presented with palpable regional recurrence had cancer in the remaining thyroid lobe (Table 4 ). Of the 8 patients in whom the primary lesion was papillary cancer, the contralateral lesions were papillary cancer in 6 patients, tall cell Variant of papillary cancer in 1 patient, and 1 patient had Undergone anaplastic transformation 120 months after the original lobectomy. In the patients in whom the primary tumor was either follicular or Hürthle cell carcinoma, 2 patients had follicular carcinoma and 2 patients had Hürthle cell carcinoma found in the remaining lobe. The 1 patient in this group who presented with distant pulmonary metastases had no cancer found in the remaining thyroid lobe. The mean follow-up for Group 2 was $72 \pm 17$ months. One patient died of unrelated Causes, 4 patients are alive with evidence of thyroid cancer, and

4 patients are alive without evidence of thyroid cancer. Two patients died with extensive thyroid cancer and the remaining two patients have been lost to follow-up.

Overall, $32(53 \%)$ of 60 patients undergoing contralateral lobectomy for WDTC had residual tumor in the remaining thyroid lobe. If the 5 patients with cervical nodal disease are included, $37(62 \%)$ of 60 patients had residual disease found at the time of their completion thyroidectomy. There was no correlation between the size of the primary tumor or the lymph node status and the occurrence of cancer in the contralateral lobe. Of the 16 patients with multifocal disease in the primary lobe, $14(88 \%)$ patients had cancer found in the contralateral lobe at completion thyroidectomy. Multifocal disease in the primary lobe was significantly better at predicting bilateral thyroid cancer then when it was not present $(p<0.01)$.

Postoperative radioactive iodine thyroid scans were performed in 53 patients. The average percent uptake on ${ }^{131} I$ thyroid scintiscan was $1: 92 \pm 0.6 \%$. Ablative therapy was administered to $26(49 \%)$ of 53 patients, whose average percent uptake on thyroid ${ }^{131} \mathrm{I}$ scan was $2.8 \pm 0.9 \%$. The average percent uptake for those patients who did not receive ${ }^{131} I$ ablative therapy was $0.57 \pm 0.1 \%$.

The overall postoperative complications included $3(5 \%)$ patients with transient RLN palsy, $5(8 \%)$ patients with transient hypocalcemia, and $1(1.7 \%)$ patient with permanent hypoparathyroidism. The complications seen in Group 1 were 3 patients with transient hypocalcemia and another 2 patients with transient RLN palsy. All of these patients had resolution of their complication by the third postoperative month. There were no cases of permanent hypoparathyroidism or RLN injury in this group. Complications encountered in Group 2 consisted of transient hypocalcemia in 1 patient and transient RLN palsy in 2 patients. One patient with extensive regional recurrence developed permanent hypoparathyroidism.

\section{Discussion}

The treatment of WDTC remains controversial. The indolent course of most patients with WDTC makes the resolution of this controversy concerning the superiority of one mode of therapy over the other difficult to assess. Many retrospective studies have supported the view that total or near total thyroidectomy results in a decreased recurrence rate $[7,8,12-15]$, a decreased rate of pulmonary metastases $[10,12]$, and improved survival compared to unilateral thyroid lobectomy $[14,15,22]$. However, in many instances the ability to make the diagnosis of WDTC is not possible intra-operatively. This results in patients undergoing a lobectomy for what turns out to be WDTC. In these patients the questions arise as to whether any residual thyroid cancer remains in the neck and what is the safest way to remove the remaining thyroid lobe and possible remaining thyroid carcinoma.

Most surgeons would agree that all thyroid cancer should be removed. The incidence of bilateral WDTC in the literature ranges from $25 \%$ to $88 \%[5,11,23-27]$, however, the significance of bilateral WDTC has been debated. Tollefsen and coworkers [26] demonstrated an incidence of occult (lesions $<1.5 \mathrm{~cm}$ ) papillary carcinoma in the contralateral thyroid lobe in $38 \%$ of total thyroidectomy specimens, but only a $5 \%$ incidence of clinically recurrent carcinoma in the opposite lobe of patients who underwent a unilateral thyroid lobectomy for 
papillary thyroid cancer. The incidence of recurrent thyroid cancer occurring in the residual contralateral lobe of the thyroid gland ranges in the literature from $4.7 \%$ to $46 \%$ (mean $7 \%$ ) of such patients $[28,29]$. These findings suggest that the high incidence of bilateral thyroid cancer may not always be clinically significant.

In this series, all patients with regional recurrence following unilateral thyroid lobectomy had significant thyroid cancer in the remaining thyroid lobe. This raises the question whether regional recurrence may have been avoided with an initial total thyroidectomy. However, because of our practice at the UMMC, it is impossible to accurately assess this statement based on data from our patient population base. Our practice of performing completion thyroidectomy in all patients with clinically significant WDTC has resulted in a very small, nonrepresentative cohort of patients who are being observed following unilateral thyroid lobectomy for WDTC. However, Rose and associates [2] did follow 82 patients following thyroid lobectomy for WDTC and found in this group 30 patients who developed regional recurrence and 8 patients who developed distant metastases. Among these $38(46 \%)$ patients, 27 went on to have a completion thyroidectomy. In 20 (74\%) of these 27 patients thyroid cancer was found in the remaining lobe. Among the remaining 7 patients who had no cancer found in the residual thyroid lobe, 5 patients presented with distant metastases. Rose and colleagues [29] also followed 34 patients who underwent prophylactic completion thyroidectomy. In this group, $21(62 \%)$ of 34 patients had WDTC found in the contralateral lobe and an additional 3 patients had cervical nodal disease alone. Only $5(15 \%)$ of these 34 patients developed recurrent disease following completion thyroidectomy and all but one was apparently cured following further surgical intervention. We observed a similar $4 \%$ recurrence rate in our comparable study group (Group 1). In Rose's series, the rate of recurrence following the initial unilateral thyroid lobectomy patients was $46 \%$ and was in keeping with the incidence of thyroid cancer found in the contralateral lobe $(62 \%)$ found at prophylactic completion thyroidectomy. Contrary to the results reported by Tollefsen and coworkers [26], this raises the question whether the high incidence of thyroid cancer found in the contralateral lobe may be the source of some of the recurrences in patients following a unilateral thyroid lobectomy for WDTC.

Unfortunately, the ability to clinically assess involvement of the contralateral lobe in the postoperative period is limited. In this series, although the majority of the contralateral tumors found at completion thyroidectomy ( 26 of 32) were $>1.5 \mathrm{~cm}$, they were not appreciated clinically by the original surgeon or at the time of their assessment for completion thyroidectomy. Other factors, such as the size of the primary tumor or lymph node involvement, were not found to be indicators of bilateral WDTC. The presence of multicentricity in the primary lobe was found to be associated with a higher incidence of bilateral thyroid cancer than when it was not present $(p<0.01)$. Others have also found that multiple foci in the primary lobe indicated bilateral disease in a significant number of patients $[24,30]$.

Since it has been shown that the incidence of unsuspected carcinoma is high, the question remains of the safest way to remove the remaining thyroid lobe in patients with WDTC who have undergone a unilateral lobectomy. Because reoperative thyroid surgery has been associated with a high morbidity [20, 26 ], some surgeons and endocrinologist have advocated ${ }^{131} \mathrm{I}$ ablation of the remaining thyroid remnant in order to achieve a total thyroidectomy [31]. This approach, however, has several disadvantages. First, several doses of radioactive iodine may be necessary in order to achieve an adequate thyroid ablation [18]. Beierwaltes and associates [32] demonstrated that it is difficult to adequately ablate large thyroid remnants ( $>5 \%$ uptake). Second, there is an additional concern over the long-term affects of ${ }^{131}$ I ablation of normal thyroid tissue causing secondary injury to the adjacent parathyroid glands [33]. Bondesen and colleagues [33] reported a series of 10 parathyroid adenomas that developed in patients who received ${ }^{13}{ }^{1} I$ ablation of their thyroid. The authors concluded that this was not mere coincidence. They further suggested that the use of radioactive iodine to ablate significant amounts of thyroid tissue, especially in the younger age group, is a risk factor for the subsequent development of parathyroid adenomas. Because of these concerns with the use of ${ }^{131} 1$ to ablate the remaining thyroid lobe, surgical resection remains the best way of removing the remaining thyroid tissue. The concerns about increased morbidity with more than a thyroid lobectomy are not necessarily justified. In experienced hands, total thyroidectomy, and more importantly secondary thyroid operations, can be performed safely with little morbidity to the patient $[9,13,24,25,27,34]$. Calabro and coworkers, [24] in a recent review of completion thyroidectomies, reported an incidence of transient hypocalcemia of $12 \%$ and transient RLN palsy of $1.5 \%$. In our series the incidence of transient hypocalcemia was $8 \%$ and transient RLN palsy was $5 \%$. Only 1 patient had permanent hypoparathyroidism, however, this was in a patient with extensive regional recurrence who underwent extensive debulking concurrent with a therapeutic completion thyroidectomy.

Ideally, there should be little need for completion thyroidectomy in situations where total thyroidectomy is routinely performed for clinically significant WDTC. Papillary carcinoma can usually be diagnosed with certainty in most cases by fine needle aspiration cytology or frozen section. Occasionally the encapsulated follicular variant may be difficult to diagnosis until permanent sections can be performed. A much more common problem is the well-differentiated encapsulated follicular or Hürthle cell neoplasm which is diagnosed as carcinoma only after permanent sections have demonstrated microscopic capsular or vascular invasion. In order to decrease the need for completion thyroidectomy, we have in the past few years performed total thyroidectomy for all such neoplasms $>4 \mathrm{~cm}$ in diameter because our previous studies showed approximately $80 \%$ of these tumors proved to be malignant after permanent microscopic study [35]. Because smaller follicular carcinomas rarely if ever are multicentric, rarely spread within the lymphatics, and rarely require ${ }^{131} \mathrm{I}$ for treatment of distant metastases, it is debatable whether this small subgroup requires completion total thyroidectomy. In this series 2 of 9 follicular carcinoma patients in Group 1 had a bilateral foci of cancer. However, in both patients, papillary carcinoma $<1.0 \mathrm{~cm}$ was found in the contralateral lobe.

Although many surgeons advocate total or near-total thyroidectomy for WDTC, some of these surgeons hesitate to do completion thyroidectomies when there is no clinical evidence to suggest bilateral disease, for fear of the added morbidity to 
the patient. This series, however, demonstrates that completion thyroidectomy can be performed safely with little morbidity to the patient. The high incidence $(43 \%)$ of thyroid carcinoma in the residual thyroid lobe in patients with no clinical evidence of disease following unilateral lobectomy suggests the necessity for re-operative intervention to eliminate an unsuspected contralateral focus of cancer. Furthermore, patients with regional recurrence in whom a significant amount of thyroid tissue remains should undergo completion thyroidectomy along with treatment of their recurrent disease as there appears to be a high percentage of residual thyroid carcinoma in the remaining thyroid lobe. Finally, multicentricity in the primary lobe was associated with bilateral thyroid disease and may be used as a guided in assessing patients for completion thyroidectomy.

\section{Résumé}

Le but de cette étude était d'évaluer l'évolution chirurgicale après thyroïdectomie totale des patients ayant un cancer thyroïdien présumé bien différencié et unilatéral (CTBD). Les données médicales de tous les patients ayant eu une lobectomie unilatérale de la thyroïde pour CTBD et qui ont eu secondairement une totalisation de la thyroïdectomie ont été revues. Entre 1980 et 1991, 60 patients ayant un CTBD ont eu une totalisation de la thyroïdectomie, quarante sept avaient un CTBD présumé unilatéral, sans argument pour une pathologie résiduelle avant la totalisation de la thyroïdectomie (groupe 1). Vingt cinq d'entre eux (53\%) se sont avérés avoir un reliquat néoplasique persistant au niveau de la région cervicale. Chez 20/47 (43\%) patients, on a retrouvé un foyer de cancer dans le lobe restant de la thyroïde. Chez 5 patients supplémentaires il n’a pas été retrouvé de cancer dans le lobe controlatéral mais une dystrophie nodulaire non suspecte. Les $13 / 60$ patients restants présentaient soit une récidive régionale (12) soit des métastases à distance (1) au moment de la totalisation de la thyroïdectomie (groupe 2). Tous les patients du groupe 2 sauf un (92\%) avaient un cancer dans le lobe restant. Une atteinte plurifocale dans le premier lobe était associée avec l'existence d'un cancer bilatéral $(p<0.01)$. Les complications ont été rares: une hypocalcémie transitoire est survenue chez $5(8 \%)$ patients, une hypoparathyroïdie définitive est apparue chez $1(1.7 \%)$ patient. Une paralysie récurentielle transitoire a été retrouvé chez 3 (5\%) patients. Conclusions: Un reliquat de TCBD a été retrouvé chez 37/60 (62\%) patients opérés d'une totalisation de thyroïdectomie. L'atteinte multifocale dans le premier lobe réséqué était associée avec une incidence élevée de cancer thyroïdien controlatéral. La totalisation de la thyroïdectomie est une procédure sans risque qui peut prévenir le développement d'une récidive régionale en éliminant un foyer de cancer non suspecté.

\footnotetext{
Resumen

El propósito del presente estudio fue valorar el resultado quirúrgico de completar a una tiroidectomía total la resección tiroidea realizada en pacientes con cáncer presumiblemente unilateral y bien diferenciado de la glándula tiroides (CTBD). Se revisaron las historias clínicas de todos los pacientes sometidos a lobectomía tiroidea unilateral por CTBD, en quienes subsiguientemente se completó la tiroidectomía, procedimiento que fue
}

realizado en 60 pacientes con CTBD en el período 1980-1991. Cuarenta y siete pacientes tenian CTBD presumiblemente unilateral, sin evidencia de enfermedad residual antes de completarse la tiroidectomía (grupo 1); en veinticinco (53\%) de estos pacientes se halló neoplasia residual en el cuello. En 20/47 (43\%) pacientes se encontró un foco de cáncer en el lóbulo tiroideo remanente y en 5 casos adicionales aunque no se encontró cáncer en el lóbulo contralateral, se halló extensión ganglionar no sospechada. Los $13 / 60$ pacientes restantes presentaron recurrencia (12) o metástasis distantes (1) en el momento de completarse la tiroidectomía (grupo 2). Todos los pacientes del grupo 2, excepto $1(92 \%)$, presentaban cáncer en el lóbulo remanente. La presencia de enfermedad multifocal en el lóbulo primario apareció asociada con cáncer tiroideo bilateral $(p<0.01)$. Las complicaciones fueron raras; se presentó hipocalcemia transitoria en $5(8 \%)$ pacientes, hipotiroidismo permanente en $1(1.7 \%)$ y parálisis parcial y transitoria del nervio laríngeo recurrente en $3(5 \%)$. Conclusiones: Se encontró CTBD en $37 / 60(62 \%)$ pacientes en quienes se completó la tiroidectomía. La presencia de enfermedad multifocal en el lóbulo primario resecado apareció asociada con una alta incidencia de cáncer contralateral. El procedimiento de completar la tiroidectomía aparece como una operación segura que puede prevenir el desarrollo recurrencia regional al eliminar focos insospechados de cáncer.

\section{Acknowledgment}

Sponsored by the R. Samuel McLaughlin Foundation, Canada.

\section{References}

1. Cady, B., Sedgwick, C.E., Meissner, W.A., Bookwalter, J.R., Romagosa, V., Werber, J.: Changing clinical, pathological, therapeutic, and survival patterns in differentiated thyroid cancer. Ann. Surg. 184:541, 1976

2. Rossi, R.L., Cady, B., Silverman, M.L., Wool, M.S., Horner, T.A.: Current results of conservative surgery for differentiated thyroid carcinoma. World J. Surg. 10:612, 1986

3. Farrar, W.B., Cooperman, M., James, A.G.: Surgical management of papillary and follicular carcinoma of the thyroid. Ann. Surg. 192:701, 1980

4. Wanebo, H.J., Andrews, W., Kaiser, D.L.: Thyroid cancer: Some basic considerations. Am. J. Surg. 142:474, 1981

5. Brooks, J.R., Starnes, F., Brooks, D.C., Pelkey, J.N.: Surgical therapy for thyroid carcinoma: A review of 1249 solitary thyroid nodules. Surgery 104:940, 1988

6. Buckwalter, J.A., Thomas, C.G.: Selection of surgical treatment for well differentiated thyroid carcinomas. Ann. Surg. 176:565, 1972

7. Grant, C.S., Hay, I.D., Gough, I.R., Bergstralli, E.J., Goellner, J.R., McConahey, W.M.: Local recurrence in papillary thyroid carcinoma: Is extent of surgical resection important? Surgery 104:954, 1988

8. Clark, O.H., Duh, Q.: Thyroid cancer. Med. Clin. North Am. $75: 211,1991$

9. Harness, J.K., Fung, L., Thompson, N.W., Burney, R.E., McLeod, M.K.: Total thyroidectomy: Complications and technique. World J. Surg. 10:781, 1986

10. Massin, J.-P., Savoie, J.-C., Gardnier, H., Guiraudo, G., Leger, F.A., Bacourt, F.: Pulmonary metastases in differentiated thyroid carcinoma: Study of 58 cases with implications for the primary tumor treatment. Cancer 53:982, 1984

11. Clark, R.L., White, E.C., Russell, W.O.: Total thyroidectomy for cancer of the thyroid: Significance of intraglandular dissemination. Ann. Surg. 149:858, 1958

12. Samaan, N.A., Maheshwari, Y.K., Nader, S., Hill, C.S., Schultz, 
P.N., Haynie, T.P., Hickey, R.C., Clark, R.L., Goepfert, H., Ibanez, M.L., Litton, C.E.: Impact of therapy for differentiated carcinoma of the thyroid: An analysis of 706 cases. J. Clin. Endocrinol. Metab. 56:1131, 1983

13. Clark, O.H., Levin, K., Zeng, Q., Greenspan, F.S., Siperstein, A.: Thyroid cancer: The case for total thyroidectomy. Eur. J. Cancer Clin. Oncol. 24:305, 1988

14. Mazzaferri, E.L., Young, R.L.: Papillary thyroid carcinoma: A 10 year follow-up report of the impact of therapy in 576 patients. Am. J. Med. 70:511, 1981

15. DeGroot, L.J., Kaplan, E.L., McCormick, M., Straus, F.H.: Natural history, treatment and course of papillary thyroid carcinoma. Clin. Endocrinol. Metab. 71:414, 1990

16. Friedman, M., Pacella, B.L.: Total verus subtotal thyroidectomy: Arguments, approaches and recommendations. Otolaryngol. Clin. North Am. 23:413, 1990

17. Ward, P.H.: The surgical treatment of thyroid cancer. Arch. Ototlaryngol. Head Neck Surg. 112:1204, 1986

18. Ramacciotti, C., Pretorius, H.T., Line, B.R., Goldman, J.M., Robbins, J.: Ablation of nonmalignant thyroid remnants with low doses of radioactive iodine: Concise communication. J, Nucl. Med. 23:483, 1982

19. Girelli, M.E., Busnardo, B., Amerio, R., Scotton, G., Casara, D., Betterle, C., Piccolo, M., Pelizzo, M.R.: Serum thyroglobulin level in patients with well-differentiated thyroid cancer during suppression therapy: Study on 429 patients. Eur. J. Nucl. Med. 10:252, 1985

20. Beahrs, O.H., Vandertoll, D.J.: Complications of secondary thyroidectomy. Surg. Gynecol. Obstet. 117:535, 1963

21. Thompson, N.W., Olsen, W.R., Hoffman, G.L.: The continuing development of the technique of thyroidectomy. Surgery 73:913, 1973

22. Mazzaferri, E.L., Young, R.L., Oertel, J.E., Kemmerer, W.T., Page, C.P.: Papillary thyroid carcinoma: The impact of therapy in 576 patients. Medicine 56:171, 1977

23. Jacobs, J.K., Aland, J.W., Ballinger, J.F.: Total thyroidectomy: A review of 213 patients. Ann. Surg. 197:542, 1983

\section{Invited Commentary}

\author{
Professor Thomas S. Reeve \\ Department of Surgery, University of Sydney, Sydney, Australia
}

Conventional wisdom has it that to come to a sound conclusion, the matter at hand should be duly considered, data collected, data analyzed, conclusions drawn, and decisions made. How often this process has been followed in relation to thyroid cancer is difficult to estimate. However, it is clear that the decisions that have been made to date result in controversy. There are a number of contradictory opinions as to what should be done and opinion in surgery in such controversial areas is difficult to resolve by logic alone. This paper makes a significant contribution towards a resolution, particularly for patients having had a lobectomy as prime treatment for well differentiated thyroid cancer (WDTC).

The problem seems to be that after treatment for WDTC patients generally do well, therefore, it is widely believed that minimal surgery will suffice for optimal results. This premise has not always been addressed in clearly logical terms and insufficient attention appears to have been given in the reporting of results as they relate to those few who die from the disease or who suffer multiple surgical operations for recurrence.
24. Calabro, S., Auguste, L., Attie, J.N.: Morbidity of completion thyroidectomy for initially misdiagnosed thyroid carcinoma. Head Neck Surg. 10:235, 1988

25. Roa, R.S., Fakih, A.R., Mehta, A.R., Agarwal, R., Raghavan, A., Shrikhnde, S.S.: Completion thyroidectomy for thyroid carcinoma. Head Neck Surg. 9:284, 1987

26. Tollefsen, H.R., Shah, J.P., Huvos, A.G.: Papillary carcinoma of the thyroid: Recurrence in the thyroid gland after initial surgical treatment. Am. J. Surg. 124:468, 1972

27. Auguste, L.J., Attie, J.N.: Completion thyroidectomy for initally misdiagnosed thyroid cancer. Otolaryngol. Clin. North Am. 23:429, 1990

28. Clark, O.H.: Thyroid nodules and thyroid cancer. In Endocrine Surgery of the Thyroid and Parathyroid Glands, O.H. Clark, editor, St. Louis, C.V. Mosby Company, 1985, pp. 56

29. Rose, R.G., Kelsey, M.P., Russell, W.O., Ibanez, M.L., White, E.C., Clark, R.L.: Follow-up study of thyroid cancer treated by unilateral lobectomy. Am. J. Surg. 106:494, 1963

30. LoGerfo, P., Chabot, J., Gazatas, P.: The intraoperative incidence of detectable bilateral and multicentric disease in papillary cancer of the thyroid. Surgery $108: 958,1989$

31. Goolden, A.W.G.: The indications for ablating normal thyroid tissue with 1131 in differentiated thyroid cancer. Clin. Endocrinol. $23: 81,1985$

32. Beierwaltes, W.H., Rabbani, R., Dmuchowski, C., Lloyd, R.V., Eyre P., Mallette, S.: An analysis of "Ablation of thyroid remnants" with 1-131 in 511 patients from 1947-1984: Experience at the University of Michigan. J. Nucl. Med. 25:1287, 1984

33. Bondeson, A.-G., Bondeson, L., Thompson, N.W.: Hyperparathyroidism after treatment with radioactive iodine: Not only a coincidence? Surgery 106:1025, 1989

34. Reeve, T.S., Delbridge, L., Brady, P., Crummer, P., Smyth, C.: Secondary thyroidectomy: A twenty-year experience. World J. Surg. 12:449, 1988

35. Gundry, S.R., Burney, R.E., Thompson, N.W., Lloyd, R.V.: Total thyroidectomy for Hürthle cell neoplasm of the thyroid. Arch. Surg. I18:529, 1983

The report by Pasieka and colleagues shows that significant residual cancer is present in the contralateral lobe (43\%) when lobectomy is done as prime treatment. The presence of WDTC in $62 \%$ of patients undergoing completion thyroidectomy provides a strong argument for further exploration when WDTC is discovered in a lobar lesion, especially when the lesions in the lobe are multifocal. Low morbidity surgery such as outlined in the paper further supports this approach. Although the residual tumor may well not kill the patients, to leave cancer in place, particularly when amenable to excision, is against all surgical principles. It can hardly be argued that cancer is good for patients, even when of more the favorable diploid status [1]. When cancer is in both thyroid lobes or significantly suspected of being in both, particularly if as Pasieka and coworkers have shown, the disease is multifocal in the excised lobe, total thyroidectomy should be done as the authors propose.

This paper clearly identifies that surgery which eradicates the whole gland is the optimal form of treatment for this type of malignancy. This supports the recent report by DeGroot and coworkers [2] and clearly suggests that patients with WDTC treated by total or near total thyroidectomy have an improved survival and decreased recurrence of their disease.

While the authors do not offer contralateral lobectomy for patients with tumors $<1 \mathrm{~cm}$ in size, they advocate surgery for co-existent or recurrent disease where clinically possible. It is 